\title{
LA MEZQUITA PRIVADA DE ‘ABD AL-RAHMAN IBN MARWAN al-YILIQI EN LA ALCAZABA DE BADAJOZ
}

FERNANDO VALDÉS FERNÁNDEZ

Universidad Autónoma de Madrid

Los trabajos que, desde septiembre de 1998, vengo dirigiendo en el edificio del Hospital Militar, en la Alcazaba de Badajoz ${ }^{[1]}$, han aportado evidencias arqueológicas, de especial valor, no sólo para el conocimiento de Bațalyaws, sino también para establecer las grandes líneas seguidas por el proceso de islamización del Garb al-Andalus.

Entre todas aquéllas deben destacarse dos: los restos de una mezquita y los de un conjunto residencial, ambos relacionados entre sí. Formaban parte, sin la menor duda, del alcázar edificado por Ibn Marwān al-Yillīiī, el fundador de Bațalyaws, entre el 875 y el 889 , y fueron reutilizados, al menos en dos fases posteriores, perfectamente documentadas y datadas entre comienzos del siglo XI y comienzos del XIII. No me referiré aquí más que a la inicial del primero de aquellos edificios -la mezquita- dejando el análisis de su última fase y del segundo para trabajos posteriores, en espera de finalizar su total excavación y estudio.

\footnotetext{
[1] Los trabajos de excavación han estado enmarcados en un proyecto general de rehabilitación y transformación del edificio en Facultad de Biblioteconomía y Documentación y en Biblioteca Regional de Extremadura. Las excavaciones arqueológicas han sido patrocinadas por la Consejería de Cultura de la Junta de Extremadura y la dirección del proyecto arqueológico ha estado sujeta a un convenio entre la Universidad Autónoma de Madrid, a través de Fundación General, y la propia Consejería de Cultura.

La primera fase de las excavaciones tuvo lugar entre los meses de septiembre y diciembre de 1998, aunque algunos detalles sólo pudieron ser investigados entre finales del 2000 y comienzos del 2001, siguiendo la dinámica determinada por el conjunto del proyecto y su difícil resolución administrativa.
} 


\section{LA MEZQUTTA DE LA ALCAZABA DE BADAJOZ}

\section{Los testimonios escritos}

De la mezquita ubicada en la alcazaba de Badajoz sólo poseíamos dos noticias documentales claras. Sus autores están separados por siete siglos de distancia.

La primera de ellas aparece recogida por al-Himyarī -un autor que vivió a caballo de los siglos XIII y XIV (LÉVI-PROVENÇAL, E., 1938, pp. XIII-XVIII; LEWICKI,T., 1975)-, pero lo escribió al-Bakrī, un príncipe walbí del XI (LÉVI-PROVENÇAL, E., 1960, pp. 159-160; alBAKRĪ,A.'U., 1982, pp. 8-9) y, seguramente, éste lo tomó, a su vez, de la desaparecida obra del historiador cordobés Ahmmad al-Rāzĩ, quien la compuso en el siglo X (al-RĀZĪ, 1975, pp. XI-CX).

El texto en cuestión narra la definitiva fundación de la ciudad de Batalyaws por 'Abd al-Rahmmān ibn Marwān ibn Yunūs, apodado al-Yilliqī. No corresponde a acontecimientos ocurridos en el 875 , fecha oficial de la creación de la ciudad y momento de erección de su muralla (TORRES BALBÁS, L., 1941, pp. 239-240; HERNÁNDEZ, F., 1967, p. 62), sino a otros acaecidos unos años más tarde, durante el reinado del emir cordobés 'Abd Allāh (888-912) y antes del fallecimiento de 'Abd al-Raḥmān ibn Marwān, seguramente en el 889 (CODERA, F., 1904, pp. 403-404 y 1917, p. 70).

"Bațalyaws [...J fue construida por 'Abd al-Raḅmān b. Marwān al-Ŷillíqi con la autorización del emir 'Abd Allāh, quien puso a su disposición albañiles y dinero. 'Abd alRaḥmān comenzó por la construcción de la aljama, de ladrillo y cal, salvo el alminar, que fue especialmente construido en piedra. Él se reservó una maqșüra. También construyó una mezquita particular en la alcazaba [...] Conservó los albañiles puestos a su disposición hasta que fueron construidas algunas mezquitas" (LÉVI-PROVENÇAL,E., 1938, p. 38).

La segunda noticia se debe al canónigo badajocense Rodrigo Dosma, quien vivió en el siglo XVI (DOSMA, R., 1870, pp. V-LXX) y dejó la única descripción conocida de la primera catedral de Badajoz:

“...en la que fue sée de Santa Maria: donde estaban tres bilos de arcos con cada siete columnas, unas lisas y otras estriadas, de toda mezcla, que tienen los capiteles trastocados, y aun basas sobrepuestas, según el poco aviso o mucha mengua del que con destrozos de diversas formas compuso tal fábrica. Son altas las columnas, que entran por la tierra y su fundamento no parece, porque estando el suelo de alrededor alto, así que se entraba por gradas, como en la iglesia de Calatrava y San Andrés, según que los mahometanos cavándolo o amontonándolo aparejan las mezquitas, conforme a su superstición, para igualarlo todo se rebinchó el templo no ha mucho tiempo, de que quien lo decía se acordaba, y fuera más acertado bajar la plaza del cementerio" (Ibidem, p. 67). 
De este texto se desprende que el edificio de la catedral de Santa María, era una adaptación de la mezquita de la alcazaba al culto cristiano. Y, se afirma de modo general, que el oratorio islámico estaba construido con piezas de distinta hechura, que para entrar se había de descender algunos peldaños, que el suelo había sufrido variaciones de nivel y que las columnas no tenían basa y estaban clavadas en el suelo. No se menciona su tamaño y nunca se afirma la diferencia radical entre todos los capiteles y columnas. Sólo que unos fustes eran lisos y otros estriados y que los capiteles estaban trastocados. Pero eso no es decir mucho. Ocurre lo mismo en tres de las cuatro fases de la mezquita mayor de Córdoba (TORRES BALBÁS, L., 1965; CRESSIER, P., 1985; EWERT, Ch., 1981 y 1996). Además, tomando como elemento de comparación idéntico ejemplo, una misma etapa cronológica de obra original, sin reutilización de piezas escultóricas más antiguas, podía conllevar, sin contradicción alguna, la diversidad estilística de los elementos utilizados. Es el caso de la fase de 'Abd al-Raḥmān II (848), en la misma aljama cordobesa, muy pocos años anterior a la mezquita de la alcazaba de Badajoz. Nadie niega hoy que sus capiteles, todos diferentes, se labraran en el mismo momento, imitando piezas tardorromanas de distinta apariencia, algunas del período godo, reempleadas en la primera fase del mismo edificio. El resultado final mantuvo una calculada estética, para dar sensación de continuidad y, en términos simbólicos, del uso de spolia procedentes de monumentos antiguos ${ }^{[2]}$.

\section{Los testimonios gráficos}

La documentación gráfica que pueda ayudarnos a reconstruir nuestra mezquita se reduce a un plano. Fue realizado en 1803 por el ingeniero militar José de Gabriel (Fig. 1). Es el documento más exacto de cuantos poseemos sobre la alcazaba antes de la Guerra de Independencia y a la erección del Hospital Militar, que lo fue en la segunda mitad del siglo

[2] En la primera fase de la mezquita mayor de Córdoba (787) todas las columnas, capiteles y cimacios son tardorromanos reaprovechados, aunque su colocación en las naves no se realizó al azar, sino que se seleccionaron las piezas que tenían un módulo más clásico para situarlas en la nave central. Cf. CRESSIER,P. (1985); EWERT, Ch. (1981), pp. 56-64. En la segunda fase, la mandada ejecutar por el emir 'Abd al-Raḥmãn II (848), los capiteles se labraron expresamente para la obra, pero, en todos los casos, son imitaciones de prototipos tardorromanos, algunos de ellos colocados en el oratorio de 'Abd al-Raḥmān I. El criterio de selección de las piezas es idéntico al seguido allí, buscando colocar ejemplares más clásicos en la nave central y en las zonas inmediatas a la quibla.

La labra de estas piezas escultóricas, perfectamente documentada por M. Gómez-Moreno, vino a demostrar la existencia de actividad artística, más allá de la puramente constructiva, en la Córdoba del momento y concuerda bien con la noticia de la fundación de Badajoz en lo que se refiere al envío de obreros. Cf. GÓMEZ-MORENO, M.(1941); TORRES BALBÁS,L. (1965), pp. 395-402; CRESSIER, P. (1985); EWERT, Ch. (1981), pp. 64-70.

Cuando el hạâyib al-Manșur amplió hacia oriente la ya por entonces enorme aljama cordobesa, no introdujo ninguna variación en el tipo de los capiteles de la fase anterior, la del califa al-Ḥakam II (961), salvo en la zona septentrional de la superficie añadida. Se labraron allí columnas y capiteles de módulo arcaizante para imitar el aparente desorden de las emplazadas en la fase colindante de 'Abd al-Raḥmân I. Cf. Ibidem (1981), pp. 88-89 y (1996), p. 211. 


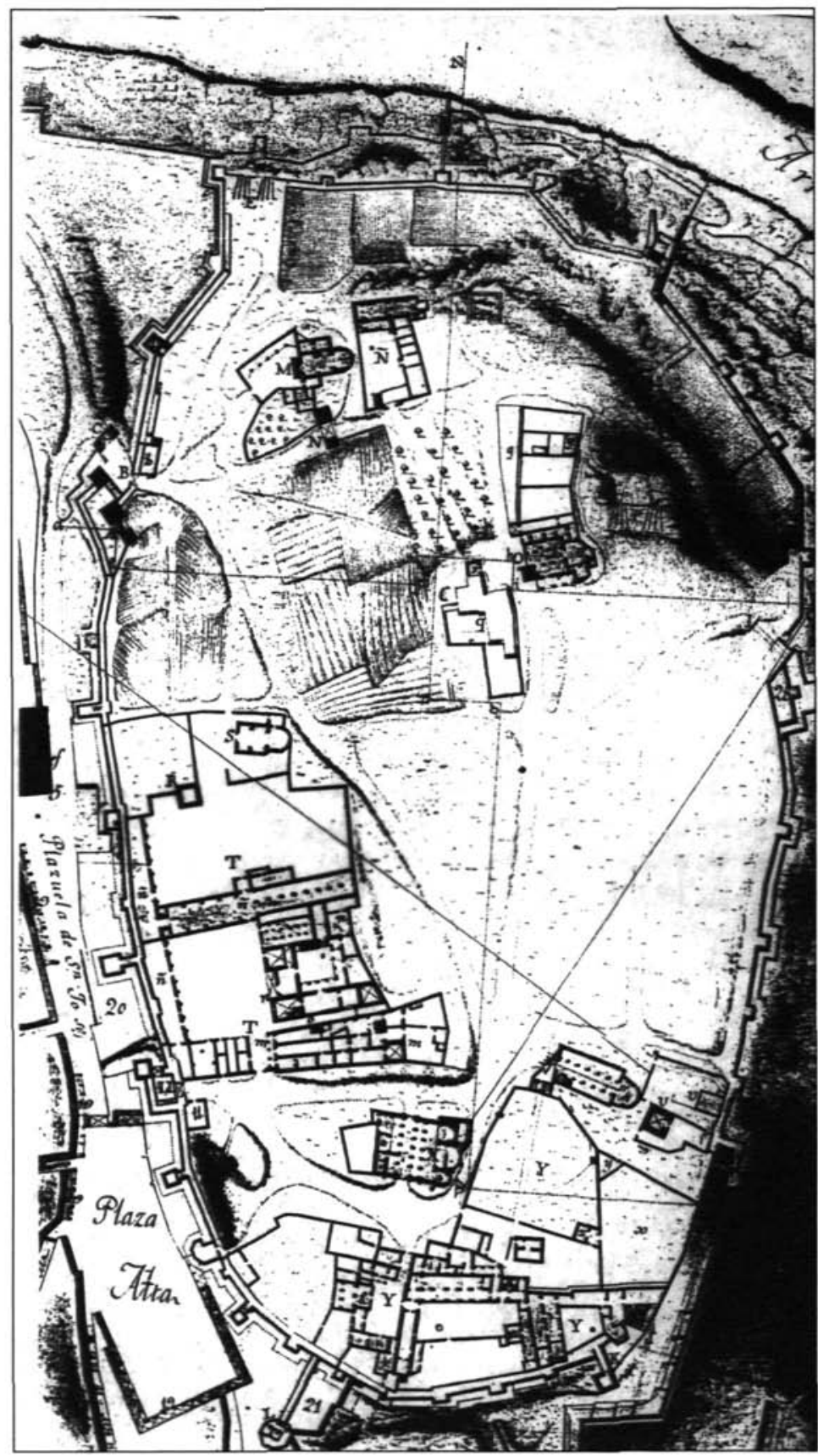

Figura 1. Detalle del plano De Gabriel (1803). 
XIX. Pueden apreciarse en él con notable detalle las edificaciones existentes en el interior del recinto amurallado ${ }^{[3]}$.

Entre los edificios representados allí merece destacarse, como objeto de nuestro interés, el conjunto de Santa María de la Sée, por tratarse de la única representación completa del primitivo templo catedralicio de Badajoz, antigua mezquita de la alcazaba en época islámica. Tiene la catedral una estructura de triple cabecera absidada, con el ábside central más ancho que los laterales. La forma de estos no es, entre sí, idéntica por completo.

El interior del edificio presenta una organización de cinco naves, la central más ancha, perpendiculares al muro meridional y separadas por columnas, salvo la última -a Occidente-, donde, en el momento de levantarse el plano, debieron haberse perdido y alguna de ellas estar embutida en una serie de muros que la subdividen. Uno de los tramos transversales, el colocado en el centro, es más ancho que los demás. Correspondería a la nave central de la mezquita. Dos puertas aparecen en los extremos de esta nave. Resulta obvio que esta organización fue el resultado de convertir el oratorio islámico en templo cristiano, continuando un esquema cuyos antecedentes están en Córdoba y se remontan al primer arte omeya de Siria (EWERT, Ch. und WISSHAK, J.P., 1981).

La interpretación de esta planta, que ha venido siendo admitida como canónica, se debe al arquitecto Leopoldo Torres Balbás (TORRES BALBÁS, L., 1943), quien la llevó a cabo a partir de una copia del plano original (Fig. 2) ${ }^{[4]}$. El fue el primero en asociar las naves

[3] Consta de dos hojas de gran tamaño, una con la planta y otra con dos secciones de la alcazaba. Se halla depositado en el Servicio Geográfico del Ejército: "Plano que manifiesta la altura del castillo antiguo de la plaza de badajoz [sic], con el detalle de su recinto formado por torreones, y muralla antigua, y de sus edificios mas principales, que son el Hospital real, el cuartel de Infanteria en las casas del Conde de la Roca, y del conde de los Acevedos, la Iglesia de Santa Maria, la de Calatrava, y otras que servian a la antigua Badajoz. Extendiendose por el lado de la poblacion a todo el frente de la Puerta de Merida, al campo de Sn. Juan, y principio de la Alameda, y por el lado opuesto basta el Rio Guadiana, Arroyo de Rivillas, y Huerta de Merida, según se previene por la Rl. Orden de 13 de Diciembre de 1803". El plano está firmado por José de Gabriel y por Jose Fuentes. La escala es de 150 varas castellanas.

[4] El proceso seguido por el insigne investigador para llevar a cabo este trabajo tiene interés en la medida en que ayuda a comprender sus evidentes errores. En realidad no le son achacables directamente a él, sino al anónimo dibujante de la copia que utilizó.

Por los años en que se escribió y publicó el artículo don Leopoldo era catedrático de Historia de la Arquitectura en la Escuela Técnica Superior de Arquitectura de Madrid, único centro, con Barcelona, donde podían cursarse en España estudios de Arquitectura. Como trabajo de curso de la materia solía encargar a sus alumnos, venidos de todos los puntos del país, el estudio de algún monumento de sus lugares de procedencia, con especial predilección por los de origen islámico, siendo la arquitectura andalusí su sujeto de especialización investigadora desde hacia mucho tiempo.

Algún alumno badajocense, podría con una cierta facilidad detectivesca buscarse su nombre, hizo el calco de la planta del plano de De Gabriel, depositado por entonces en la Comandancia de Ingenieros de Badajoz, pero cometió algunos errores de apreciación al pasar a limpio su croquis original. Le dio a los ábsides un perfil poligonal demasiado acusado y al muro occidental, el de los pies, una alineación más paralela a la cabecera que la visible en el original. Pero quizás la mayor omisión no ha sido patente hasta que hemos podido levantar un plano detallado de los restos catedralicios preservados en la fábrica del Hospital Militar. La planta real no coincide con la copia escolar, publicada después por L. Torres Balbás. El alumno de arquitectura no tuvo aparentemente en cuenta que el original estaba realizado en varas castellanas y al pasarlo a la escala métrica decimal se produjo una diferencia de proporciones. Esta discrepancia, aun no perjudicando gravemente a la interpretación teórica del antiguo edificio, dificultó la busqueda y estudio de los restos arqueológicos preservados. 


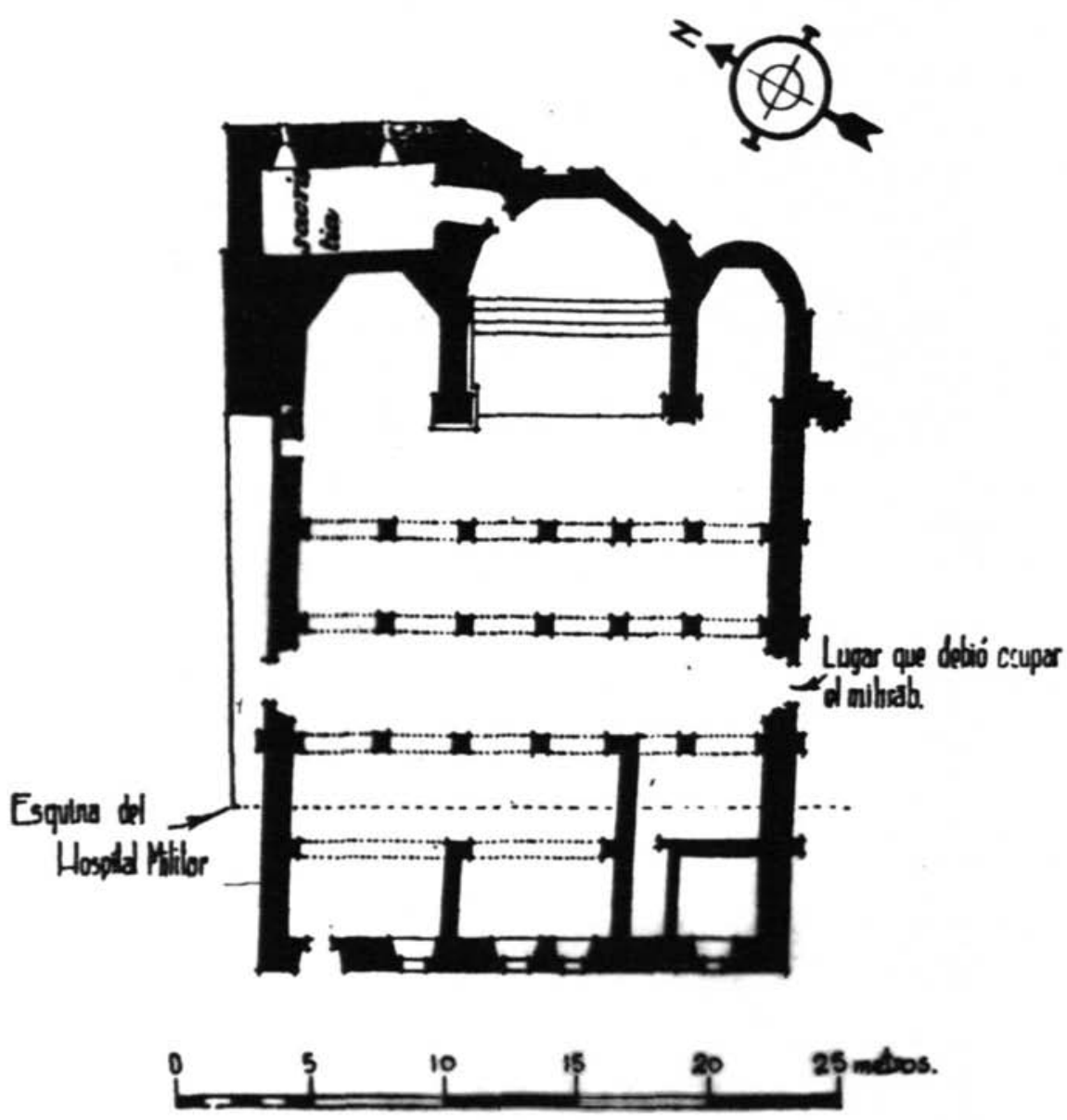

Badajoz. Alcazaba. Planta de la mezquita convertida en iglesia, según estaba en la primera mitad del siglo XIX.

Figura 2. Plano publicado por L. Torres Balbás. 
de la catedral de Santa María con la mezquita de la alcazaba que menciona al-Bakrī y describe, en el siglo XVI, Rodrigo Dosma; en reconstruir las dimensiones aproximadas del edificio ${ }^{\mid 51} \mathrm{y}$ en suponer que las dos puertas practicadas en los extremos axiales de la nave central -la meridional- se correspondían, respectivamente, con el emplazamiento del miḅräb y con su acceso principal (Ibidem, p. 469). Así mismo, interpretó las dependencias visibles a los píes de la catedral como producto de la reorganización arquitectónica de la zona mediante el procedimiento de desmontar "...algunos arcos de la última fase por este lado [el occidentall, probablemente para disponer coro y capilla bautismal". (Idem). Consideró, además, que el oratorio islámico tenía cinco naves, basándose no sólo en la evidencia gráfica, sino en la analogía con las mezquitas de Algeciras, Écija, Jaén, Málaga, Tortosa, Almonaster la Real y Madinat al-Zabrā' (Ibidem, p. 468, nota 1).

Si bien las teorías de este insigne investigador son correctas en términos generales, sobre todo si tenemos en cuenta la documentación de que dispuso y las evidencias materiales accesibles por entonces, no dejó de incurrir en ciertos errores de bulto, muy patentes al describir la capilla mayor y esbozar la cronología de las laterales y de las torres de la cabecera $^{|6|}$. El resto de los errores no se le puede reprochar. Sólo se han detectado una vez practicadas las excavaciones arqueológicas de que nos ocupamos aquí.

\section{Los testimonios arqueológicos}

A pesar de que nuestro conocimiento de la mezquita resulta parcial debido a la destrucción de algunas de sus partes, los restos excavados permiten llevar a cabo una reconstrucción bastante aproximada de sus elementos principales (Fig. 3). Se han descubierto mínimas porciones de su límite oriental y bastante más de la mitad de su cabecera o qibla -quibla o alquibla, en castellano-, con los restos del miḅrāb. También ha logrado exhumarse la cimentación de tres de las columnas de una de las naves. Sin embargo, no estamos completamente seguros de que los vestigios, perfectamente localizados, pero no excavados en su totalidad, del lado occidental de la catedral lo fuesen realmente de la mezquita. Queda la duda, por su falta de paralelismo con las naves del edificio y por la diferencia constructiva, de que fuera una ampliación llevada a cabo al cristianizarse el oratorio islámico.

\section{La qibla}

A juzgar por las dimensiones de lo conservado, el testero de la mezquita tenía, al convertirse en catedral, unos $18 \mathrm{~m}$ de ancho y la profundidad, en dirección S-N, no es muy

[5] Las medidas exteriores serían, según este autor y en términos aproximados, de $18.80 \times 18.20 \mathrm{~m}$. La anchura de las naves laterales de $2.80 \mathrm{~m}$ y de 3.55 , la central. Cf. TORRES BALBÁS, L. (1943), p. 468.

[6] Ibidem, p. 469. Aparenta desconocer la sección de la alcazaba, obra también de De Gabriel, donde se representa la catedral vista desde Oriente. 


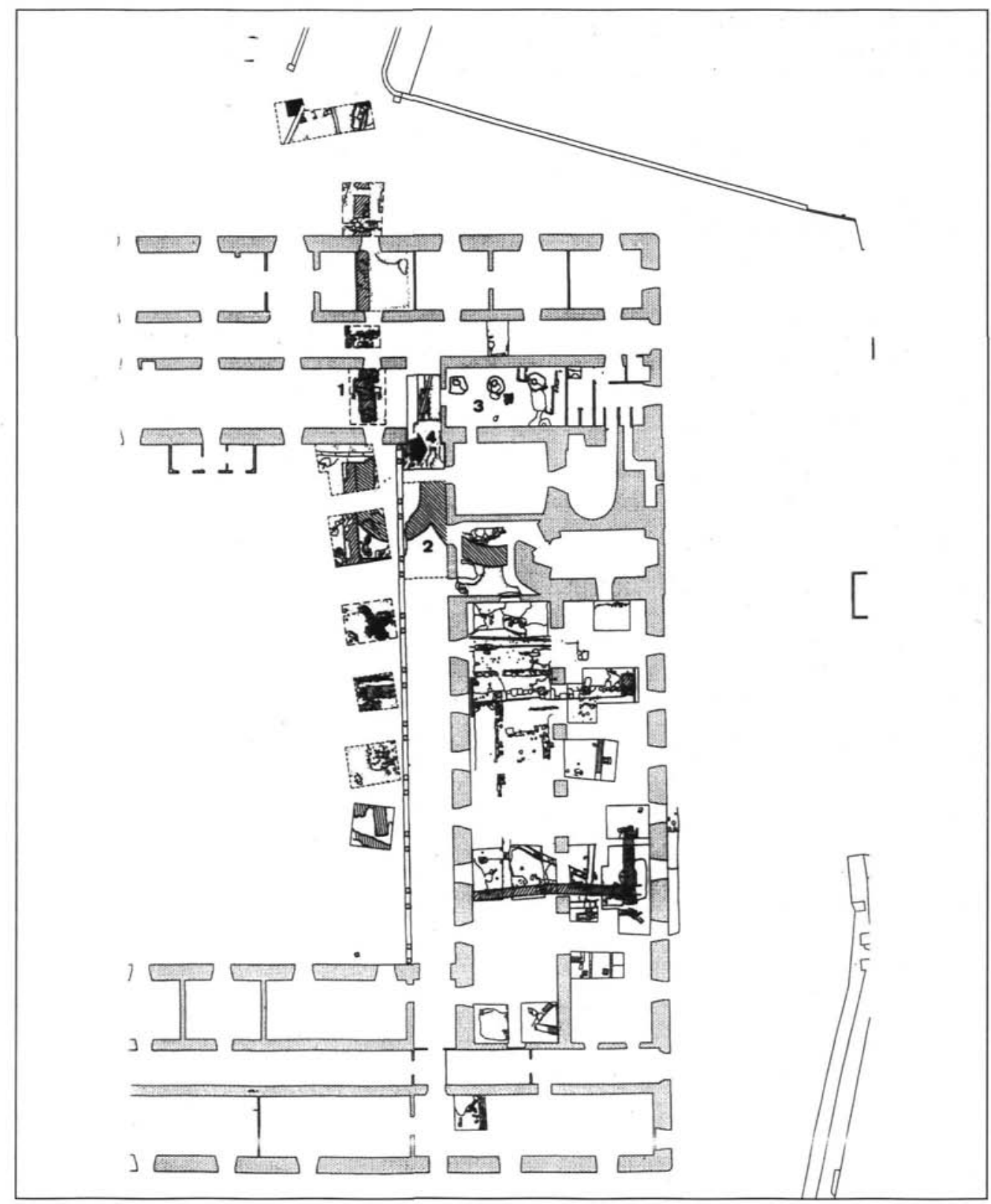

Figura 3. Plano general de los restos aparecidos en el Ala Norte del antiguo Hospital Militar de Badajoz:

1. Parte de la quibla, con los restos del mibrāb; 2 . Ábasides de la catedral de Santa María de la Sée; 3. Restos de la cimentación de las columnas de la mezquita; 4 . Fragmento de elucido, que marca el límite oriental del oratorio (Escala 1:300, aproximadamente) 
diferente, $17.64 \mathrm{~m}$. Pueden apreciarse, con todo, variaciones estructurales entre su extremo sudeste, en la zona ocupada por los vestigios del miḅrāb y su continuación, al exterior del Hospital Militar.

La porción de muro en que se localiza el resto del miḅrāb está edificada en un tipo de enplecton -piedra más grande, en ambas caras del muro, con mampostería en el interior- de regular calidad, si bien, su parte más occidental, la que coincide con la zona del nicho, fue de sillares de granito. De este tipo de fábrica pétrea no se conservan más que algunas mínimas partes y las líneas de cal de sus camas ${ }^{[7]}$. Su anchura es de $1.04 \mathrm{~m}$ y su longitud máxima conservada de $3.69 \mathrm{~m}$. Por el contrario, las porciones del muro afloradas hacia el oeste, saliendo incluso del hospital, están realizadas en un tipo de mampostería de menor calidad, más menuda, y con un empleo mucho menos evidente del enplecton.

En la cara norte - a $0.65 \mathrm{~m}$ del extremo occidental y a $2.20 \mathrm{~m}$ del oriental- destaca lo que fue la parte inferior de un contrafuerte, también de granito. Conserva un frente de $0.84 \mathrm{~m}$ y sobresale de la cara del muro $0.41 \mathrm{~m}$. La posición de su eje coincide con la del miḩräb, ubicado en la cara contraria del paramento, señalando ambos la misma dirección sur, aunque, de hecho, haya una diferencia de algunos pocos centímetros entre uno y otro. Resulta evidente, por fábrica, dimensiones y ausencia de otro semejante, en la porción conservada de la qibla, que servía para señalar, desde el exterior del edificio, la posición del mihrāb, al interior.

\section{El mibrāb (Fig. 4)}

Está construido con mampostería de piedra y cal ${ }^{[8]}$. Por dentro y por fuera tiene planta cercana a la mitad de un cuadrado, con una especie de resalte o brazo lateral, hacia oriente, que hubo de tener su simétrico en dirección contraria, aunque haya desaparecido.

Adosado a la prolongación oriental del mibrāb quedan los restos de una cimentación de argamasa de cal, algo rehundida en el centro. Su forma es cuadrada, regular, y, a pesar de faltarle una esquina, se puede reconstruir perfectamente la planta original ${ }^{19}$.

Por delante del nicho, pegados con cal a lo que fue cara interior del muro de la quibla, aparecieron dos muretes de ladrillo. Uno tenía sus piezas formando un delgado pan-

[7] En el contexto arquitectónico de Badajoz, donde los materiales constructivos disponibles siempre fueron de muy mala calidad, el empleo de sillares de granito supone un modo harto cuidadoso y caro de levantar un edificio o alguna de sus partes.

[8] Anchura de la pared: $31 / 33 \mathrm{~cm}$.

Profundidad interior: $25 \mathrm{~cm}$.

Amplitud del vano: $60 / 62 \mathrm{~cm}$.

[9] Tres de los lados conservados tienen $33 \mathrm{~cm}$ y el incompleto $18 \mathrm{~cm}$. A título de comparación cabe señalar que la única basa de mármol aparecida in situ en toda el área excavada en el Hospital Militar tiene unas dimensiones de $29 \times 29 \mathrm{~cm}$. La cimentación en cuestión hubo de soportar una basa muy poco más grande, como demuestran, además, su forma y lo plano de su superficie. 


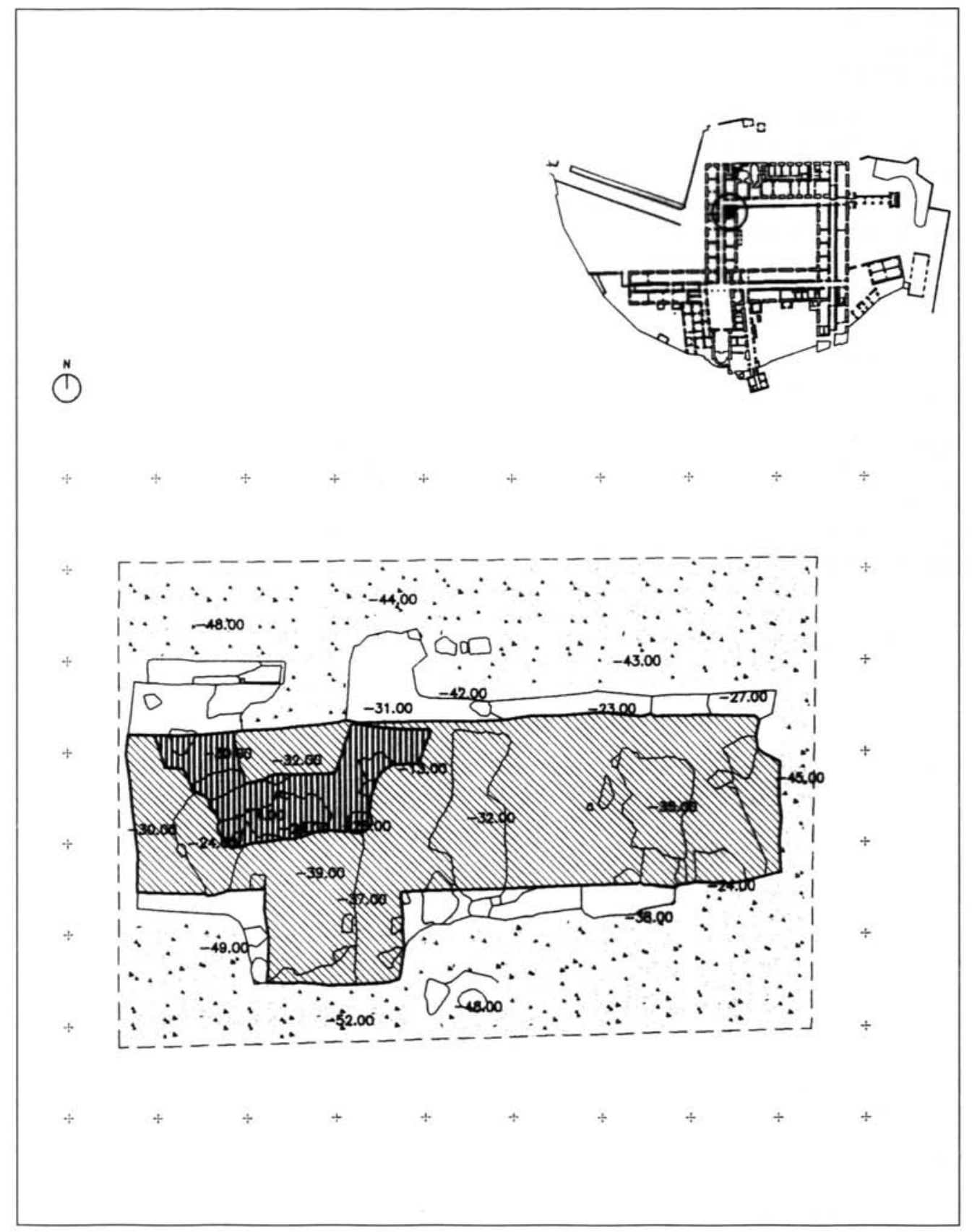

Figura 4. Planta del mib̧râb. La separación entre cruces es de $1 \mathrm{~m}$. 
derete. El otro, sin embargo, las tenía perfectamente colocadas a soga, trabadas con cal, y era más grueso. Conservaba éste una altura de tres hiladas. El primero de ambos fue el revestimiento de una sepultura, relacionada con varios fragmentos de hueso aparecidos junto a él. El segundo, sin embargo, se alzaba delante mismo del hueco del nicho, sin llegar a cubrir su frente del todo. Es obvio que este segundo murete se edificó para tapiar el mib̆rāb, cuando la mezquita se convirtió en templo cristiano.

En la zona inferior del ángulo SE del nicho resta un diminuto fragmento de enlucido rojo. De su posición se desprende que el mihräa estaba levantado entre 5 y $7 \mathrm{~cm}$ sobre el nivel del suelo en la nave del oratorio.

La revisión de todos los escasos restos aún visibles induce a pensar que nuestro miḥrāb debió ser de planta circular y hallarse forrado de mármol, sobre una banda o zócalo encalada y pintada de rojo. La transición entre la actual forma, de tendencia cuadrangular, y la original, semicircular, debía producirse mediante la adición de estrechas losas de mármol adheridas al fondo del nicho o por simple enlucido de cal. Su aspecto externo adoptaba la tradicional forma de arco entre dos columnas. De una resta el apoyo de la basa, pero nada podemos decir, por ahora, del cuarto de esfera superior ${ }^{[10]}$.

\section{El perimetro del oratorio}

Del perímetro de la mezquita sólo poseemos la evidencia aportada por la qibla -el muro meridional-y otra mínima, descubierta al excavar el extremo oeste de la galería del gran patio central, muy próxima al mihrāb y a la primera de las cimentaciones descritas más arriba. Se trata de un pequeño fragmento, -apenas $15 \mathrm{~cm}$ de lado- de enlucido (Fig. 3:4), colocado todavía in situ. Fue parte del revestimiento del muro oriental de la mezquita, precisamente en la cara exterior del espacio religioso ${ }^{[111}$. Gracias a él podemos trazar el límite arquitectónico del oratorio, en ese mismo lado, aunque no conozcamos las características morfológicas del muro que le sirvió de soporte ${ }^{[12 !}$. También permite advertir cómo el edificio del alcázar continuaba en esa dirección, en una sucesión de habitaciones, apenas constatadas arqueológicamente por algunos, muy escasos e informes, restos de muros y de pavimentos teñidos de rojo.

No sabemos cuales eran los límites occidental y septentrional de la mezquita, si bien, podemos suponer, en el caso de este último, que su trazado debía coincidir con el muro

[10] Para las cuestiones relacionadas con el origen, significado y tipología del mibräb cf PAPADOPOULO,A. (Ed.). [11] Este pequeño resto se ha conservado, protegido, debajo del pavimento del edificio, una vez finalizada su rehabilitación.

[12] Su aparición fue casual y, en mucha medida, sorprendente. La fábrica del muro había desaparecido por completo, pero lo hizo cuando la tierra que llenaba el espacio sobrepasaba la altura del enlucido. Ésta lo sujetó cuando desapareció la mampostería a la que estuvo adherido. Recogimos algunos fragmentos más, pero desperdigados en el transcurso de las muchas remociones sufridas allí por el subsuelo del hospital, para instalar distintas canalizaciones. La forma de aparecer todas ellas fue una demostración más de lo intacto de la pieza en cuestión. 
de Santa María y situarse entre la cara sur del único ábside conservado en todo su alzado -el norte- y la fachada externa del hospital, perceptiblemente alineada con la torre de la

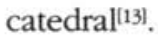

Elemento interesante a considerar, a la hora de intentar la delimitación de la mezquita, es que el muro meridional del tercero de los ábsides, exhumado en el transcurso de la excavación, no es una prolongación de la alquibla. Está adosado a otro, de indudable estructura andalusí e idéntica orientación que la cabecera de la mezquita, pero desplazado algo más de $0.50 \mathrm{~m}$ hacia el sur. No parece haber formado parte del mismo espacio arquitectónico, sino de una sala adosada, quizás la misma en la que estuvo integrado el fragmento de enlucido estudiado antes, adherido originalmente a su pared occidental.

Los motivos por los cuales el ábside no aprovechó directamente o se apoyó en este muro o en el de la qibla, en el caso hipotético de haberse prolongado hacia oriente, pueden suponerse. El anónimo arquitecto responsable de convertir la mezquita en catedral y de realizar las trazas de la cabecera triabsidada no debió considerar suficientemente resistentes los muros del edificio islámico como para soportar el peso de la bóveda de crucería de la futura cabecera, cuya altura era, además, superior. El nuevo paramento, idéntico al documentado en otras zonas de la fase cristiana, se realizó, al menos en su cimentación, con un durísimo aparejo de cal y canto, muy característico de las obras militares leonesas del siglo XIII' ${ }^{[14]}$.

En otro orden de cosas, es difícil saber, a partir de los datos arqueológicos recuperados, si los muros del edificio estaban reforzados por contrafuertes en todo su perímetro. Lo seguro es la presencia de uno marcando, al exterior, el lugar donde, dentro de la sala, estaba emplazado el mị̆rāb y su edificación, al menos en la zona inferior, con sillares de granito. La escasa altura de los restos conservados impide asegurar la continuidad de la misma estructura granítica hasta la línea de cubierta. Habida cuenta de la escasa calidad constructiva constatable en las antiguas construcciones de Badajoz, incluyendo la misma

[13] Los restos de muro salidos a la luz allí mientras este trabajo estaba en vías de publicación son parte de la fachada norte de la catedral, pero su estructura, con contrafuertes hacia el interior y hacia el exterior podrían estar hablando a favor de una reforma del edificio islámico en aquel punto preciso, quizás relacionada con la erección de la torre o de la portada principal. Es uno de los aspectos que quedan por aclarar respecto a la mezquita y a su estado inmediatamente anterior a la conquista leonesa.

[14] Este tipo de aparejo fue muy usado, según ha demostrado J.A. Gutiérrez González, en la edificación de castillos y recintos de villas meseteñas llevados a cabo, entre 1170 y 1220, por Fernando II y Alfonso IX, sobre todo en las zonas fronterizas con Castilla. Ejemplos son: Mansilla de las Mulas (León) -hacia 1281; Villalpando (Zamora) -1170-1180-; Toro (Zamora) -1188-1195-; Almanza (León) -hacia 1191-; Castronuevo (Zamora) -finales del siglo XII-; San Pedro de Latarce (Valladolid) -hacia 1203-; Laguna de Negrillos (León) -hacia 1205-; Rueda del Almirante (León) -hacia 1206-; Belver de los Montes (Zamora) -castillo y cerca: 1211 y 1214 - y en la propia muralla de León entre 1214 y el siglo XIV. También se utilizó en fortificaciones de la Extremadura leonesa: Galisteo y Granadilla. Cf. GUTIÉRREZ GONZÁLEZ, J.A. (1995), pp. 77-79 y 346, fig. 81. 
alcazaba $^{[15]}$, en las que lo habitual son las obras de tapia y, en casos contados, de mampostería de piedra ${ }^{116}$, el uso de granito es muestra de riqueza arquitectónica. En el propio recinto amurallado pueden contarse con los dedos de la mano los lugares donde se emplea ese material -p. ej., en las puertas del Capitel y del Alpendiz- y siempre con un predominio de los conceptos decorativos sobre los estructurales. Además, los sillares suelen ser reaprovechados de antiguas construcciones romanas ${ }^{[17]}$. Así, no resultaría raro que toda la zona del mihrāb, no sólo su parte baja, se acabase en piedra, tanto al exterior como al interior, para destacar, en un edificio de relativa calidad constructiva, su importancia dentro del conjunto. Eso lleva a pensar, de ser cierto, que la cabecera de la mezquita daba al exterior del edificio, quizás a un patio. De lo contrario, dicha ostentación arquitectónica resultaría inútil.

\section{La organización de las naves}

La información de que disponemos para reconstruirla es muy escasa, aunque resulte suficiente para determinar cómo se estructuraba la sala de oración en sus aspectos esenciales (Fig. 3:3).

Pervive la cimentación de tres columnas, cuya situación respecto del arranque de los ábsides de la catedral, añadidos después de la conquista leonesa de 1230, hace suponerlas pertenecientes a la más oriental de las naves de la mezquita ${ }^{[18]}$. Se trata, en los tres casos,

[15] Toda la fortificación de Badajoz está construida con tapia, debido a la escasa utilidad constructiva de la piedra local. Sólo en el año 1030, durante el reinado de Abū Muhammad 'Abd Allāh b. al-Afțas, primer monarca de la dinastía aftasí, se llevó a cabo una reforma de los muros de la alcazaba. Lo afirma el geógrafo onubense alBakrī, contemporáneo de aquél "Al principio las murallas de Badajoz estaban construidas con tapia. Después, en el 421 (= 9 ene. 1030 - 28 dic. 1030) fueron reconstruidas, como abora lo están, con cal y piedra tallada" (LÉVIPROVENÇAL,E., 1938, pp. 2 S 58). Esta reforma la hemos podido documentar arqueológicamente, de modo inequívoco, en la Puerta de Carros y en una gran parte del lienzo occidental, pero no se trata en realidad de una obra realizada con sillería, como podría deducirse del texto en cuestión, sino de sillarejo y mampostería de piedra. A pesar de todo, la referencia que de ese material se hace en la crónica viene justificada por su evidente novedad en el marco de los usos constructivos de la capital batalyusí. Cf. También VALDÉS,F. (1999).

[16] No es rara la combinación de ambos tipos de fábrica. En estos casos, lo habitual es comenzar con mampostería, para asegurar la estabilidad y la impermeabilidad, y continuar con tapia. En la vecina iglesia de Santa María de Calatrava, fechada como la sée en torno a 1230 y cuyos restos fueron reexcavados hace pocos años, la parte baja de los muros, la única conservada, es de mampostería, pero sabemos, merced a una visita de 1634, que "La iglesia es edificada todas las paredes de piedra lentiéndase mampostería de piedral y es de tres naves armada sobre pilares de mármol con arco de ladrillo y encima de ellos de tapiería de piedra con bormigón de cal...". PÉREZ,P. (1929), p. 410.

[17] La penuria de piedra llega hasta el extremo de emplear granito de diferentes calidades en una misma superficie constructiva - p. ej., puerta del Capitel-. Es probable que los sillares se arrancaran de distintos edificios y lugares

[18] Los sondeos abiertos en otras zonas aledanas del hospital, allí donde, por simple cálculo matemático debieran haberse emplazado otras columnas, no aportaron ningún testimonio complementario. Es evidente que las obras de edificación del hospital, primero, $\mathrm{y}$ las repetidas e indocumentadas intervenciones que afectaron al subsuelo, después, hicieron desaparecer el resto de las cimentaciones. 
de macizos cilíndricos de argamasa de cal y algo de grava, en cuyo centro se abren sendos y profundos alvéolos circulares. No eran el soporte de las columnas del oratorio, sino, como se demuestra en los tres ejemplos, el sitio donde estaban clavadas, sin basa alguna que las apease. De las dimensiones de los huecos -todos poseen un diámetro de $0.36 \mathrm{~m}$ - se desprende una cierta homogeneidad, - al menos en estos tres casos-, en el tamaño de los fustes $^{[19]}$.

La prolongación hipotética de la línea que une sus centros geométricos coincide casi exactamente con el centro del miḅrāb, aunque sea perceptible una desviación hacia el oeste ${ }^{[20]}$. Eso supone, de no mediar otros elementos de juicio, que aquél no se hallaba situado, relacionándolo con el cimiento de la columna más cercana, en el eje de la nave central, como fue norma en las mezquitas anteriores y coevas; ni siquiera en el de una de las laterales. Su localización, aceptando como indudable el testimonio gráfico aportado por el plano de De Gabriel, habría sido la línea de columnas que separaba, a oriente de la mezquita, la cuarta de la quinta nave. Eso se antoja, como poco, sorprendente.

Por lo demás, el hecho de haberse demostrado por vía arqueológica la inexistencia de basas y la fijación de los fustes al suelo, clavándolos directamente en macizos de argamasa, refrenda el testimonio de Rodrigo Dosma cuando afirma, refiriéndose a nuestro edificio: "Son altas las columnas, que entran por la tierra y su fundamento no parece..." (DOSMA,R., 1870, p. 67).

\section{La mezquita privada de 'Abd al-Raḥmān ibn Marwān (Fig. 5).}

La conjugación de las informaciones aportadas por la excavación arqueológica y la que nos ofrecen las fuentes, escritas y gráficas no resulta fácil, si admitimos la veracidad indudable de unas y otras y aceptamos que la mezquita de la alcazaba, tal y como la encontró el rey Alfonso IX de León, en 1230, no había sufrido ningún cambio desde su erección por 'Abd al-Raḥmān al-Ŷilliqiî, a fines del siglo IX.

\section{El área de la sala de oración}

Conocidas las dimensiones de la cabecera de la catedral de Santa María, cuya anchura alcanzaba los $17.64 \mathrm{~m}$, forzoso es aceptar, tal y como manifiestan los testimonios y la car-

[19] Estos macizos cilíndricos aparecieron desmoronados por uno de sus lados. Las roturas son el testimonio del modo en que fueron arrancadas las columnas, cuando se levantó el edificio. Los responsables del trabajo picaron en uno de los costados, una vez desmontada la techumbre y las partes altas de las naves, e inclinaron cada fuste hasta que, rompiendo la argamasa que lo fijaba al suelo, los fueron dejando libres.

[20] Es de pocos centímetros y se produce con respecto a la actual pared oriental de la estancia, edificada sobre el muro este de la mezquita. Quizás quedaba corregida en alzado o el muro del oratorio no coincide más que en sus aspectos generales con el del actual edificio. 


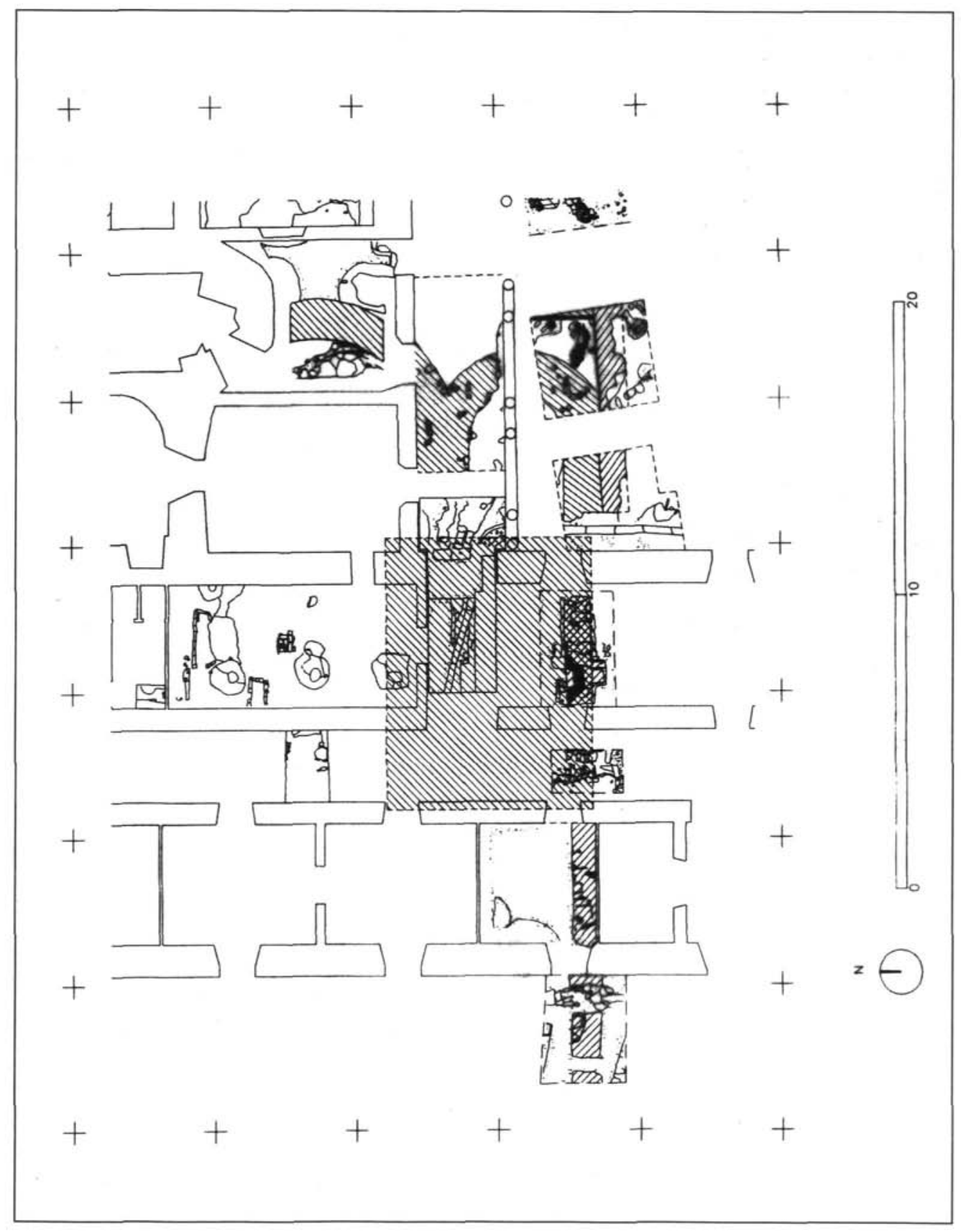

Figura 5. Reconstrucción del área ocupada por la primera mezquita. 
tografía modernos, que la mezquita poseía idénticas dimensiones, por aquel lado. Pero eso resulta, en un contexto andalusí del siglo IX, manifiestamente excesivo para un oratorio privado. Mucho más si, en caso de ser su planta rectangular, aquel costado era uno de los dos más cortos del edificio.

Otro aspecto que resulta desconcertante es la posición del mibrāa con respecto a la quibla. Si el muro que mira a La Meca tuvo, desde su origen y hacia occidente, la longitud que la excavación ha puesto de manifiesto, nuestro nicho habría estado emplazado muy cerca del extremo oriental, en un ángulo de la sala, sin ser ni su centro, ni el de nave alguna: en la línea de la columnata que servía de separación a las naves cuarta y quinta, leídas de oeste a este. Hasta ahí concuerdan los datos documentales con los arqueológicos.

\section{La posición del mibrāa y el tamaño de la sala de oración}

Todas las mezquitas cronológicamente anteriores a la fundación de Badajoz tienen el mihrābsituado en el eje de la nave central, tanto las mayores de las grandes ciudades o de ciertos establecimientos militares -Damasco (Siria) ${ }^{[21]}$, Busra (Siria) ${ }^{[22]}$, Harrán (Turquía) $^{[23]}$, Bagdad (Iraq) ${ }^{[26]}$, Raqqa (Siria) ${ }^{[25]}$, Fusțāț (Egipto) ${ }^{[26]}$, Cairuán (Túnez) ${ }^{[27]}$, El Cairo (Egipto) ${ }^{[28]}$, al-Aqsà de Jerusalén (Palestina) ${ }^{[29]}$, y el ribāt de Susa (Túnez) ${ }^{[30]} \mathrm{y}$, en al-Andalus, Córdoba' ${ }^{\mid 31]}$ y Madinat al-Zahrā' ${ }^{[32]}$, -como las privadas o semiprivadas de los palacios-

[21] Fechada en el año 88 H. (= 12 dic. 706 - 30 nov. 707). Cf. CRESWELL,K.A.C. (1969), I, p. 186, fig. 90.

[22] En la llamada Mezquita de 'Umar, edificada entre el 19 ray̆ab 101 (= 4 feb. 720$)$ y fines del $102 \mathrm{H}$. (= 30 jun. 721). Ibidem, II, p. 488, fig. 546.

[23] Datada entre 744 - 750. Ibidem, II, pp. 645 - 646.

[24] Construida por el califa abbasí al-Manșūr en el 149 H. (= 16 feb. 766 - 5 feb. 767). Cf. CRESWELL,K.A.C. (1940), pp. 35 - 36, fig. 26.

[25] Obra del mismo soberano que fundó a Bagdad, 155 H. (= 13 dic. 771 - 1 dic. 772 ). Ibidem, I, pp. 45 - 46, fig. 33.

[26] La mezquita de 'Amr, fuese cual fuese el momento en que se finalizó, poseía tres mibrāb. Los tres, según Creswell (Ibidem, p. 193, fig. 170), estuvieron dispuestos simétricamente a lo largo de la quibla. El central exactamente en el eje del edificio.

[27] El mibrāb y la cúpula que lo antecede están fechados en el 248 H. (= 7 mar. 862 - 23 feb. 863). Ibidem, pp. 215 y 308 , figs. 180 y 237.

[28] La mezquita de Ibn Țülūn, en El Cairo, fue levantada entre el 263 y el $265 \mathrm{H}$. (= 24 sep. 876-22 ago. 879). Ibidem, p. 339, fig. 257.

[29] El mihräb de esta mezquita, sea de la época que sea, está situado en el mismo eje transversal del edificio. En opinión de Creswell, debe datarse, como muy tarde, durante el reinado del califa fatimí al-Zähir (1021 - 1035). Cf. CRESWELL,K.A.C. (1969), I, pp. 21 - 25 y (1940), II, pp. 119 - 126, fig. 119.

[30] La mezquita, fechada en el 206 H. (= 6 jun. 821-26 mayo 822), tiene una estructura especial, debida a la función del edificio. El mibräb, sin embargo, se mantiene en el centro exacto de la quibla. Ibidem, p. 168 , fig. 156.

[31] Las tres primeras fases de la mezquita mayor de Córdoba, fechadas, respectivamente, a principios de rabi ${ }^{\prime} \mathrm{I}$ del 170 H. (= 3 jul. $786-21$ jun. 787) (TORRES BALBÁS,L., 1965, pp. 342-369), en ỹumädà I del 324 H. (= diciembre 848 ) (Ibidem, pp. 386 - 402) y a 4 de ramaḍãn de 350 H. (= 16 oct. 961) (Ibidem, pp. 477 - 569) colocaron un mibräb en el eje mismo de la nave central.

[32] La mezquita de la ciudad palatina de Madĩnat al-Zabrā', cerca de Córdoba, se concluyó en mayo del 941. Tuvo el mịnrāb también centrado. Cf. PAVÓN, B. (1965), fig. 1. 


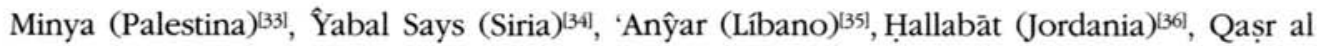
Ḥayr al-Garbī(Siria) ${ }^{[37]}$, Qașr alł̣ayr al-Šarqī (Siria) ${ }^{[38]}$, la pequeña de Jān al-Zabīb (Palestina) ${ }^{[39]}$, Jirbat al-Mafŷar (Palestina) ${ }^{\mid 40]}$, Mšattà (Jordania) ${ }^{[41]}$, Qașr al-Tuba (Siria) ${ }^{[42]}$, y el enorme palacio 'abbasí de Ujayḍir (Iraq) ${ }^{\mid 43}$ — destinados a servir al culto de una sola persona y de su más inmediato círculo íntimo. Fuerza es, por lo tanto, suponer que nuestro oratorio tuvo el nicho en el centro de su quibla.

Aceptado este hecho y habida cuenta de haber estado limitado a oriente por un muro que se situaba exactamente debajo del actual colindante con el patio, como se desprende del fragmento de enlucido estudiado antes, y siendo la distancia entre aquél y el centro del nicho de $2.74 \mathrm{~m}$, puede deducirse que la mezquita, duplicando esa mitad de la cabecera, tuvo una anchura cercana a los $5.50 \mathrm{~m}$, medidos por la cara interior de la quibla ${ }^{[46]}$. Esta magnitud se aviene bien con la proporcionalidad mantenida por otras mezquitas semejantes, anteriores y posteriores, conocidas dentro y fuera de al-Andalus. Cabe establecer una comparación no sólo con los alcázares mediorientales -Minya ${ }^{[45]}$, Ŷabal Says ${ }^{[46]}$, 'Anŷar ${ }^{\mid 47]}$, Qușayr al-Ḥallabāt ${ }^{[48]}$, Qașr al-Ḥayr al-Šarq1 ${ }^{1491}$, Jirbat al-Mafŷar ${ }^{[501}$, Mšattà|(51), Ujayḍir ${ }^{[52 L}$, sino

[33] CRESWELL,K.A.C. (1969), II, pp. 383-384.

[34] Ibidem, p. 476, fig. 538.

[35] Ibidem, p. 479, fig. 540. Este es uno de los pocos casos en que el mihrāb presenta una ligera desviación respecto del eje principal de la mezquita.

[36] Edificado en el 109 H. (= 28 abr. 727-15 abr. 728). Ibidem, pp. 502-505, fig. 555.

[37] En el palacio no se ha constatado la existencia de ningún oratorio, pero si en el vecino jän o posada, donde el mibrāb ocupa el centro de la quibla. Ibidem, pp. 506-506, fig. 562.

[38] Ibidem, pp. 530-531, fig. 576.

[39] Ibidem, p. 505.

[40] Ibidem, p. 559, fig. 605.

[41] Ibidem, pp. 583-584, fig. 636. El palacio fue construido en el 126 H. (= 25 oct. $743-12$ oct 744).

[42] En este palacio no existe, propiamente, una sola mezquita, sino cuatro habitaciones con sendos nichos orientados hacia La Meca. En opinión de Creswell podría tratarse de oratorios. Ibidem, pp. 640 - 641, fig. 661.

[43] Aceptando la atribución cronológica de K.A.C. Creswell, se habría edificado en torno al 159 H. (= 31 oct. 775 18 oct. 776). Cf. CRESWELL,K.A.C. (1940), II, pp. 74-76, fig. 59.

[44] La distancia de los extremos del nicho a los extremos conservados de la quibla es de $0.44 \mathrm{~m}$, por el lado oeste, y de $2.36 \mathrm{~m}$, por el este. La del centro geométrico de aquél a los extremos del muro es de $0.95 \mathrm{~m}$, al occidente, y $2.74 \mathrm{~m}$, al oriente.

[45] Su mezquita tiene una anchura de 13.10 x 19.42 m, de profundidad. Cf. CRESWELL,K.A.C. (1969), II, pp. 383 384, fig. 448.

[46] 9.34 x 9.48 m. Ibidem, p. 476, fig. 538.

[47] A pesar de tratarse de un palacio, sus dimensiones lo convierten en una pequeña ciudad. Su oratorio tiene, aproximadamente, $47 \times 30$ m. Ibidem, p. 479, fig. 540 .

[48] 11.80, de ancho, x $10.70 \mathrm{~m}$, de profundidad. Ibidem, pp. 502-505, fig. 553.

[49] Sólo se conserva una parte del oratorio, dentro del recinto grande, de los dos que forman este monumento. Su anchura, medida en la fachada del patio, suponiendo que la arcada occidental de aquél tenga la misma amplitud que la oriental $-3.28 \mathrm{~m}$ - es de $30.79 \mathrm{~m}$. La profundidad alcanza los $21.79 \mathrm{~m}$. Ibidem, II, pp. 530-531, fig. 576 .

[50] 17.10, de anchura, x $23.60 \mathrm{~m}$, de profundidad. Ibidem, pp. 583-584, fig. 636.

[51] 13.40, de anchura, x 27.30, de profundidad. Ibidem, pp. 583-584, fig. 636 .

[52] A pesar de la enormidad de este palacio fortificado posee un oratorio proporcionalmente muy reducido que, sin duda, refuerza la atribución concebida por K.A.C. Creswell (1940), II, pp. 74-76, fig. 59. 
también con al-Andalus, donde, a falta de casos anteriores más significativos, poseemos la mezquita del palacio de la Aljafería, en Zaragoza ${ }^{[53]}$. Nos movemos, por lo tanto, en el marco de unas magnitudes muy razonables, para una construcción de nuestras características (Fig. 1). Sin embargo, todas las partes de la quibla excavadas hasta ahora, a pesar de la destrucción de algunas porciones intermedias, sobrepasan bastante esa longitud, hasta alcanzar, como el lado oriental, los casi $18 \mathrm{~m}$. Eso y las apreciables diferencias constructivas constatadas entre el extremo este y el oeste de ese muro nos llevan a pensar en una ampliación, hacia occidente, del primitivo oratorio.

A la misma conclusión llegamos al analizar los motivos que justifican la existencia de una hilada de columnas en el mismo eje del miḅrāb, en contra de la lógica que presidía la organización en planta de este tipo de edificios. Si la cabecera de la catedral alcanza los $17.64 \mathrm{~m}$ de longitud es obligado atribuirle la misma longitud al costado oriental de la mezquita al que se adosaron los ábsides, pues la arqueología no ha sacado a la luz ningún muro que le sirviese de hipotético cierre septentrional inmediatamente antes de su conversión en templo cristiano. La sala de oración islámica también parece haber sido ampliada hacia el norte ${ }^{[54]}$.

Los restos de nuestro mihrāb muestran, además, unas proporciones perfectamente concordes con un probable menor tamaño de la sala de oración, comparadas con las habituales en otras mezquitas palatinas. Sólo, excepcionalmente, el conservado en la Aljafería resulta desproporcionado en dimensiones con respecto al de su sala de oración. Quizás esta peculiaridad deba achacarse al intento de imitar el tamaño del mandado realizar por el califa al-Ḥakam II (961-976) en su ampliación de la aljama de Córdoba ${ }^{551}$ o, con mayor seguridad, a cuestiones constructivas derivadas de la rigurosa lógica arquitectónica que preside la planta del palacio zaragozano.

Queda por explicar la situación del nicho. En una mezquita de, aproximadamente, $18 \times 18 \mathrm{~m}$, resulta excéntrico, demasiado próximo al extremo oriental y muy separado del occidental, que se halla, como señalé antes, al exterior del hospital. Eso me lleva a plantear dos hipótesis interpretativas. O se colocó de modo asimétrico en el primitivo oratorio o, redundando en las suposiciones anteriores, el edificado por 'Abd al-Raḥmān al-Ŷillīîi fue ampliado hacia occidente.

[53] La mandó edificar el segundo de los reyes taifas de Zaragoza, entre 441-447/475 H. (= 5 jun. 1049/31 mayo 1082 - 20 mayo 1083). Su planta es octogonal y tiene un diámetro que no alcanza, en ninguna de sus magnitudes máximas, los $6.00 \mathrm{~m}$. Cf. EWERT,Ch. (1978), Beilage 7.

[54] Cuando este artículo ya estaba en prensa pudimos excavar el muro septentrional de la catedral y toda el área inmediata a la cabecera y, efectivamente, no descubrimos muro alguno que abogase en contra de esta hipótesis.

[55] El diámetro del gran mihrāb cordobés, que es octogonal, es de 2.86 m (TORRES BALBÁS,L., 1965, fig. 276), lo que constituye una magnitud desusada. El de la primera mezquita mayor de Bagdad, labrado en un solo bloque de mármol, tiene $1.29 \mathrm{~m}$, de anchura, por, apenas, $0.40 \mathrm{~m}$ de profundidad (CRESWELL,K.A.C., 1940, II, pp. 35-36, fig. 26); el de la aljama de Kairuán, $1.98 \times 1.58 \mathrm{~m}$ (Ibidem, p. 308, fig. 237); el de la de Ibn Ṭülūn, en El Cairo, 1.19 x $1.02 \mathrm{~m}$ (Ibidem, p. 339, fig. 227) y las de las dos enormes mezquitas de Sāmarrä', la mayor y la de Abú Dulaf, de 2.59 x $1.75 \mathrm{~m}$ y de $1.94 \times 1.04$, en dos edificios que tienen, respectivamente, $240 \times 156 \mathrm{~m}$ y $135 \mathrm{x}$ $213 \mathrm{~m}$ (Ibidem, p. 254, fig. 205 y 278 , fig. 223). 
Esta segunda posibilidad me parece mucho más probable, no sólo por las diferencias morfológicas detectables entre los extremos este y oeste de la alquibla, sino por la persistencia de la tradición, en lo que se refiere al emplazamiento del mihrāb, en el eje mismo de todas las mezquitas públicas y privadas anteriores a la nuestra, incluyendo el preclaro ejemplo de las tres primeras fases de la aljama de Córdoba y de Madinat al-Zabrä'. No creo razonable suponer, aunque no posea la certeza absoluta, que el oratorio privado de la alcazaba de Badajoz fuese la excepción a esta arraigada regla.

$\mathrm{Si}$ hubo un agrandamiento pudo conservarse por respeto y como único el viejo miḩrāb de Ibn Marwān ${ }^{[56}$. No habría sido el primer caso. Así se hizo en Córdoba, cuando el primer ministro - bâyi $i b$ - del califa Hišām II agrandó por tercera vez la aljama, en $377 \mathrm{H}$. (= 3 mayo $987-20$ abril 988) y conservó, por respeto y por motivos políticos, el magnífico de al-Ḥakam II, dejándolo desplazado y rompiendo la estricta simetría que había presidido hasta entonces todas las ampliaciones previas. No es inverosímil que también en Batalyaws tuviera lugar un fenómeno semejante.

Para determinar cuáles eran las dimensiones de la mezquita en dirección norte es preciso apoyarse en muy cortas evidencias. La distancia entre los centros geométricos de los alvéolos donde fueron clavados los fustes es, siempre, de $2.86 \mathrm{~m}$ y entre el más meridional y la qibla, en el límite mismo del mibräb, median $5.93 \mathrm{~m}$. En ese punto la información arqueológica disponible deja abierto un interrogante, porque en toda esa área del edificio el subsuelo apareció tan removido - por haber sido zona de enterramiento, cuando aún existía la catedral de Santa María, y por las remociones llevadas a cabo en varios momentos, para mejorar o cambiar las infraestructuras del hospital- que no permaneció indemne, si lo hubo, el mínimo vestigio de cimentación, fuese de muro o de columna. De este hecho se deriva, habiendo espacio suficiente para intercalar un apoyo más entre la qibla y la primera de las cimentaciones, el planteamiento de dos hipótesis: o el límite norte coincidía con ese primer cimiento de columna y su profundidad era de $5.93 \mathrm{~m}$ o se hallaba en algún otro lugar más hacia el sur. En este segundo caso cabría admitir, a su vez, dos posibilidades: 1) los artífices de la ampliación dejaron la expresada distancia de $5.93 \mathrm{~m}$ entre la primera columna y la qibla, respetando el área de la primera mezquita; 2) colocaron otro apoyo, a $2.86 \mathrm{~m}$ del primero aparecido, rompiendo el espacio primitivo o, quizás respetándolo. Si lo hicieron así su profundidad original habría sido de $3.07 \mathrm{~m}$. No puedo resolver la incógnita, por ahora.

Sea cual sea la hipótesis correcta, con un aula de 5.93 ó de $3.07 \mathrm{~m}$, los parámetros probables se adecuan bien a lo atestiguado en otros monumentos de semejantes características. Nada puede afirmarse sobre la forma de cierre de todo el perímetro. Pudo ser un muro, una columnata o una combinación de ambos sistemas. Creo, con todo, improbable, la presencia de apoyos intermedios, columnas o pilares, en los muros de esa primera fase. Tampoco puede hablarse de la existencia o no de patio. En todo caso, la mezquita priva-

[56] Nada obliga en la tradición islámica a que, aun siendo lo más habitual, cada mezquita tenga un solo mibräb, de hecho las hay que poseen varios pero lo descubierto en el curso de nuestras excavaciones no da pié a suponer la existencia de ningún otro. 
da estaba inscrita en un marco arquitectónico mayor -el alcázar- y rodeada de otros espacios en, al menos, dos de sus lados. Queda por esclarecer el esquema de todo el conjunto.

\section{CONCLUSIÓN}

La mezquita que el emir omeya 'Abd Allāh permitió edificar a 'Abd al-Raḥmān alŶillīīi a cambio de su acatamiento, aun constituyendo un privilegio digno de un príncipe ${ }^{\text {577], }}$ tenía unas proporciones modestas. La realidad arqueológica, a pesar de lo complejo de su interpretación, ha acabado por acercarnos a los textos, aunque sólo sea de modo conceptual.

Las dimensiones de Santa María de la Sée, confirmadas y matizadas por las excavaciones, resultaban demasiado exiguas, con sus alrededor de 18 x $18 \mathrm{~m}$, para un templo de sus características. Eso era muy evidente para los conquistadores leoneses, quienes, en cuanto las circunstancias resultaron políticamente favorables, comenzaron la edificación de una catedral más grande, la actual de San Juan Bautista, en un área menos constreñida que la de la alcazaba. Por el contrario, aceptando el testimonio de los textos y la lógica acuñada en los monumentos clásicos del Islam, una mezquita privada de esas mismas dimensiones era incontestablemente excesiva, mucho más si la comparamos con las de otras construcciones palaciales del Oriente Medio. El enorme palacio abbasí de Ujayḍir (Iraq) tenía un oratorio de $24.20 \times 15.65 \mathrm{~m}$ y, sin ir más lejos, la primera fase de la aljama de Córdoba era un cuadrilátero de $79.02 \times 78.88 \mathrm{~m}$, patio incluido, con una sala de oración, siempre en términos muy aproximados, de unos $39.51 \times 78.88 \mathrm{~m}$. Es imposible defender, conocidas estas magnitudes, que la mezquita privada de Ibn Marwãn tuviese, ella sola, la mitad de la anchura de la mayor cordobesa de 'Abd al-Rahmān I. Esas proporciones serían dificultosas de aceptar hasta para la desconocida aljama de Bațalyaws.

Ahora bien, nadie ha mantenido nunca que la mezquita del alcázar del Fundador se hubiera conservado sin el menor cambio desde su erección, entre el 875 y el 889 , hasta su conversión en catedral cristiana, en 1230. La arqueología ha venido a demostrar lo contrario con bastante exactitud.

Se edificó, al menos la parte baja de sus muros, a base de mampostería de piedra, empleando la técnica del enplecton -piedras grandes en las dos caras y núcleo de otras más menudas trabadas con cal-, según el modo oriental introducido $-\mathrm{O}$ reintroducido- en al-

[57] La fundación, con el permiso del emir, de una mezquita privada no deja de tener un cierto paralelismo con las llamadas "mezquitas de tribu" o lugares concretos de oración de algunas tribus árabes existentes ya en la época del propio Profeta, aunque desconozcamos las características arquitectónicas de estos lugares y, desde luego, no podamos asociarlas morfológicamente a las mezquitas posteriores a la mayor de Damasco (construida en el 706). Eran un signo de la autonomía tribal preislámica conservada después del Islam. Con el tiempo estas mezquitas se convirtieron en un elemento de disgregación y muchos versados en la Ley islámica se replantearon la oportunidad de permitirlas. Cf. PEDERSEN.J. (1989). 
Andalus por los arquitectos omeyas. Sólo el centro de su cabecera se levantó con sillares de granito, de los que sólo se nos han conservado las líneas de cal de sus camas. No podemos afirmar con certeza, siendo bastante probable, la continuación de este tipo de fábrica en todo el alzado del paramento hasta la línea de cubierta. En el centro de esta zona de sillares sobresale un contrafuerte, del mismo material pétreo, cuya función pudo ser estructural, pero, sobre todo, simbólica. Marcaba, al exterior, la zona ocupada por el mihrāb, al interior. Carecemos de vestigios de otros contrafuertes, ni fuera ni dentro de la fábrica todavía visible.

La planta pudo ser cuadrada o rectangular. En el primero de los casos la profundidad de su eje alcanzaría los $5.93 \mathrm{~m}$, medidos desde su cara interna. En el segundo, los 3.07. Resultaría, de ser cierta esta segunda hipótesis, que la sala sería más ancha que profunda, siguiendo el esquema marcado por la gran mezquita de Damasco. Ignoramos si hubo patio precediendo a la parte cubierta, pero es bastante probable suponerla trasdosada por una zona sin techar -patio o no-, cuya existencia daría sentido al contrafuerte granítico, innecesario si la mezquita hubiera estado embebida por ese costado en un macizo arquitectónico. Tampoco nos ha llegado información sobre el modo de abrirse a las habitaciones circundantes. Pudo tener puertas hacia las laterales y un pórtico con columnas hacia el norte, pero este extremo no rebasa el terreno de la mera hipótesis.

Del espacio interior apenas resta información alguna. Pudo tener alguna subdivisión a base de columnas, pero el tamaño del espacio no las hacía estrictamente necesarias. En el subsuelo no ha permanecido el mínimo rastro de cimentación que ponga de manifiesto la presencia de tales apoyos, pero esta ausencia puede achacarse a motivos fortuitos, más relacionados con el posterior empleo del área como cementerio, después de la segunda mitad del siglo XIX, y de la instalación de infraestructuras soterradas, para atender a las necesidades del Hospital Militar. De esta misma causa se desprende la ausencia de restos de pavimento.

El muro de la qibla que constituía la cabecera de la sala de oración hubo de tener unas dimensiones cercanas a los $5.50 \mathrm{~m}, 6.00 \mathrm{~m}$ como máximo, medidos por el interior. En su centro, por el mismo lado, se abría el nicho del mibrāb, elevado unos pocos centímetros sobre el nivel del suelo. Estuvo solado con mármol -quedan señales de las losas-y, con cierta seguridad, revestido del mismo material. Lo flanquearon dos columnas, sobre basas cuadradas, como testimonia el apoyo de una de ellas conservado in situ. Se orienta exactamente a Mediodía, como fue habitual en las mezquitas de al-Andalus a partir del precedente acuñado por la aljama cordobesa. Cuando la mezquita se transformó en catedral el mihrāb fue tapiado intencionadamente.

Dada la cercanía cronológica entre la primera ampliación de la mezquita mayor de Córdoba, levantada por el emir 'Abd al-Raḥmān II, y la fundación privada de 'Abd alRaḥmān al-Ŷillīīi, puede afirmarse, por comparación con los testimonios arqueológicos localizados en el subsuelo de la aljama cordobesa por el arquitecto Félix Hernández, que la batalyusí es una copia, a escala reducida, de ésta. La imitación formal del prototipo cordobés no resulta sorprendente si damos crédito a la noticia consignada por al-Bakrī (ver más arriba) acerca de la participación en la obra de obreros enviados por el propio emir 'Abd Allāh. El uso de patrones arquitectónicos consagrados en la principal obra religiosa 
de la dinastía omeya occidental supone no sólo una lógica emulación artística. En sentido simbólico, representa un acto adicional de acatamiento por parte del rebelde Ibn Marwān y de reafirmación de la autoridad de la dinastía reinante.

En un momento muy posterior a su erección la mezquita privada de Ibn Marwān sufrió una substancial ampliación, hacia el oeste y hacia el norte. La primera sala de oración quedó convertida entonces en la esquina SE de la nueva. Sin embargo, el mihraab no parece haber sufrido modificación alguna, aun habiendo quedado desplazado de su primitiva posición axial. No nos consta la erección de ningún otro. El respeto a la tradición y al propio fundador de la ciudad justifican su conservación íntegra hasta la conversión en catedral y, después, por el hecho, premeditado, de su ocultación detrás de una pared, hasta la edificación del Hospital Militar. Lo que permanece visible es el resultado de haber cortado el muro septentrional de la sée, antiguo de la mezquita, a la altura del pavimento. Es, apenas, la cepa de lo que allí hubo, preservado, con grandes dosis de fortuna, casi exactamente debajo de las losetas que hemos pisado hasta el comienzo de las obras de rehabilitación del edificio.

\begin{tabular}{|l|l|l|c|}
\hline MEZQUITA & CRONOLOGÍA & DIMENSIONES (*) & MIب̣RĀB (**) \\
\hline Minya & Omeya & $13.10 \times 19.42$ & $1.62 \times 1.12$ \\
\hline Ŷabal Says & Omeya & $9.34 \times 9.48$ & $1.07 \times 1.35$ \\
\hline Hallabāt & Omeya, $727-728$ & $11.80 \times 10.70$ & 1.20 de anchura \\
\hline Jirbat al-Mafŷar & Omeya & $17.10 \times 23.60$ & 2.50 de anchura \\
\hline Mšattà & Omeya, $743-744$ & $13.40 \times 27.30$ & $1.62 \times 1.48$ \\
\hline Ujayḍir & Abbasí, ¿775-776? & $24.20 \times 15.65$ & $1.05 \times 0.52$ \\
\hline Aljafería & Taifa, $1049-1083$ & $\pm 6.00 \varnothing$ & $1.93 \times 1.94$ \\
\hline Badajoz & Omeya, $875-889$ & $5.50 / 6.00 \times 3.07 / 5.93$ & $0.60 / 0.62 \times 0.25$ \\
\hline
\end{tabular}

(*) Anchura $x$ profundidad del oratorio, en metros

(*) Anchura x profundidad del mibraab, en metros

Comparación entre las dimensiones de varias mezquitas privadas y su correspondiente miḅràb. 


\section{BIBLIOGRAFIA}

\section{Fuentes árabes}

AL-BAKRĪ, A.U. (1982): Geografía de España (Kitab al-Masalik wa-l-Mamalik). Introducción, traducción, notas e índices por Eliseo Vidal Beltrán. Zaragoza.

LÉVI-PROVENÇAL, E. (1938): La Péninsule Ibérique aun Moyen Age d'après le Kitāb ar-Rawḍlmi țār fí bुabār al-aḳtār d'ibn 'Abd al-Mu'nim al-Himyarì. Leiden.

Al-RĀZĪ (1975): Crónica del Moro Rasis. Ed. de Diego Catalán y Mª. Soledad de Andrés. Madrid.

\section{Fuentes romances}

DOSMA, R. (1870): Discursos Pátrios de la Real Ciudad de Badajoz. Edición de Vicente Barrantes. Badajoz.

\section{Historia y Arquitectura}

CODERA, F. (1904): "Los Benimeruán, llamados los Gallegos, en Mérida y Badajoz". Revista de Aragón, 5. Pp. 187 - 190, 237 - 242, 286 - 289, 331 - 338 y 401 - 407.

CODERA, F. (1917): "Los Benimeruán en Mérida y Badajoz". En: Estudios críticos de Historia árabe española (Segunda serie). Madrid.

CRESSIER, P. (1985): "Les Chapiteaux de la grande Mosquée de Cordoue (oratoire d'Abd arRaḥmān I et d'Abd ar-Raḥmān II) et la sculpture des chapiteaux à l'époque émirale". Madrider Mitteilungen, 25. Pp. 216 - 281.

CRESWELL, K.A.C. (1940): Early Muslim Architecture. Oxford University Press.

EWERT, Ch. (1978): Spanisch-islamiscbe Systeme sich kreuzender Bögen. III. Die Aljeferia in Zaragoza. Berlín.

EWERT, Ch. (1981): Forschungen zur almobadischen Moschee. Lieferung 1: Vorstufen. Maguncia.

EWERT, Ch. (1996): "La presencia del Islam. I. El califato de Córdoba y su estela". En: Historia del Arte de España. Dirigida por X. Barral. Barcelona. Pp. 203 - 224.

EWERT, Ch. und WISSHAK, J.-P. (1981): Forscbungen zur almobadischen Moschee. Lieferung 1: Vorstufe. Maguncia.

GÓMEZ-MORENO, M. (1941): "Capiteles árabes documentados". Al-Andalus, 6. Pp. 422 - 427.

GUTIÉRREZ GONZÁLEZ, A. (1995): Fortificaciones y feudalismo en el origen y formación del reino leonés (siglos $\mathrm{IX}-\mathrm{XIII}$ ). Universidad de Valladolid.

HERNÁNDEZ, F. (1967): "Los caminos de Córdoba hacia noroeste en época musulmana". AlAndalus, 32. Pp. 37 - 358.

HILLENBRAND, R. (1989): "Architecture de la mosquée". ER. T. VI. Pp. $664-676$.

LÉVI-PROVENÇAL, E. (1960): "Abū 'Ubayd al-Bakrī". EI², I, pp. 159 - 161.

LÉVI-PROVENÇAL, E. (1965): España Musulmana, has la caída del califato de Córdoba (7111031 de J.C.). Instituciones y vida social e intelectual. En: Historia de España, dirigida por R. Menéndez-Pidal. T. V. Madrid.

LEWICKI, T. (1975): "Ibn 'Abd al-Mu'nim al-Himyari". ER', III, pp. 697-698. 
PAPADOPOULO, A. (Ed.) (1988): Le Mị̂āb dans l'architecture et la religion musulmanes. Leiden - Nueva York - Copenhague - Colonia.

PAVÓN, B. (1965): Memoria de la excavación de la mezquita de Madinat al-Zahrā'. Madrid. PEDERSEN, J. (1989) "Masdjid". EF. T. VI. Pp. 629 - 664.

PÉREZ, P. (1929): "La Encomienda de Calatrava". Revista de Estudios Extremeños, 3. Pp. 405-413.

TORRES BALBÁS, L. (1943): "La mezquita de la Alcazaba de Badajoz". Al-Andalus, 8. Pp. 466470.

TORRES BALBÁS, L. (1941): "La Alcazaba almohade de Badajoz". Al-Andalus, 5. Pp. 155-174.

TORRES BALBÁS, L. (1965): Arte bispanomusulmán. Hasta la caída del califato de Córdoba. En: Historia de España, dirigida por R. Menéndez-Pidal. T. V. Madrid. Pp. 331-788.

VALDÉS, F. (1999): "Las etapas constructivas de la Alcazaba de Badajoz". En Bataliús, II. Nuevos estudios sobre el reino taifa. Madrid. Pp. 149-168. 